\title{
The Effect of Turbo Cyclone Installation on 4 Stroke Motor Cycle on Fuel Consumption and Exhaust Emissions
}

\section{Pengaruh Pemasangan Turbo Cyclone pada Sepeda Motor 4 Tak terhadap Konsumsi Bahan Bakar dan Emisi Gas Buang}

Syahrul Huda ${ }^{*}$, Wawan Purwanto ${ }^{1}$, Budi Utomo Wisesa ${ }^{2}$

\begin{abstract}
This research examines the effect of installing a Turbo Cyclone on a 4 stroke gasoline engine on fuel consumption and exhaust emissions. This research is a quantitative study using experimental research methods. The 4 stroke petrol engine used is the Yamaha Jupiter MX 135 cc. The data were processed in several stages of analysis using the mean formula, fuel consumption, the percentage formula, and comparing the results of data analysis from each treatment. From the results of data analysis, it was found that the installation of the Turbo Cyclone had an effect on fuel consumption and exhaust emissions from the 4 stroke engine. The best effect is obtained from the installation of the Turbo Cyclone after the carburetor, fuel consumption shows a decrease of up to 8\%, exhaust emissions show a decrease in HC levels by $9 \%$ and an increase in CO2 levels by $1 \%$.
\end{abstract}

Keywords

Turbo Cyclone, fuel consumption, Exhaust emissions

\begin{abstract}
Abstrak
Penelitian ini mambahas pengaruh pemasangan Turbo Cyclone pada mesin bensin 4 Tak terhadap konsumsi bahan bakar dan emisi gas buang. Penelitian ini merupakan penelitian kuantitatif dengan metode penelitian eksperimen. Mesin bensin 4 Tak yang digunakan adalah Yamaha Jupiter MX 135 cc. Data diolah dengan beberapa tahapan analisis menggunakan rumus mean, konsumsi bahan bakar, rumus persentase, dan membandingkan hasil analisis data dari masing-masing perlakuan. Dari hasil analisis data didapatkan adanya pengaruh dari pemasangan Turbo Cyclone terhadap konsumsi bahan bakar dan emisi gas buang dari mesin 4 Tak tersebut. Pengaruh yang paling baik didapat dari pemasangan Turbo Cyclone setelah karburator, konsumsi bahan bakar menunjukkan penurunan mencapai $8 \%$, emisi gas buang menunjukkan penurunaan kadar $\mathrm{HC}$ sebesar $9 \%$ dan peningkatan kadar $\mathrm{CO}_{2}$ sebesar $1 \%$.
\end{abstract}

\section{Kata Kunci}

Turbo Cyclone, Konsumsi Bahan Bakar, Emisi Gas Buang

${ }^{1}$ Fakultas Teknik, Universitas Negeri Padang

Jl. Prof. Dr. Hamka No.1 Fakultas Teknik, UNP, Kampus UNP Air Tawar Barat, Padang, Sumatera Barat, Indoesia

${ }^{2}$ Magister Teknik Mesin, Universitas Pancasila

Jl. Raya Lenteng Agung No.56-80, RT.1/RW.3, Srengseng Sawah, Jakarta, Kota Jakarta Selatan, Daerah Khusus Ibukota Jakarta 12640, Indonesia

*syahrulhuda1997@gmail.com

Submitted : March 12, 2021. Accepted : April 15, 2021. Published : April 25, 2021. 


\section{PENDAHULUAN}

Pertumbuhan jumlah kendaraan bermotor membawa dampak positif dan negatif, dampak positif dari semakin banyaknya kendaraan bermotor adalah semakin mudahnya mendapatkan alat transportasi dan mempersingkat waktu tempuh pejalanan.Sedangkan dampak negatifnya yaitu semakin tingginya kebutuhan bahan bakar dan masalah pencemaran lingkungan yang disebabkan oleh gas buang dari kendaraan bermotor. Meningkatnya pertumbuhan kendaraan bermotor menyebabkan penggunaan bahan bakar minyak (BBM) di sektor transportasi juga meningkat, BBM merupakan hasil penyulingan dari minyak bumi yang merupakan hasil tambang yang ketersediannya terbatas karena minyak bumi bukan energi tebarukan dan terus berkurang sehigga menimbulkan masalah pada ketersediaan jumlah bahan bakar yangketersediaannya semakin hari semakin berkurang sedangkan kebutuhan semakin meningkat, meningkatnya jumlah penggunaan bahan bakar ini juga menyebabkan meningkatnya jumlah emisi yang dihasilkan oleh gas buang kendaraan kendaraan.

Emisi gas buang dan konsumsi bahan bakar merupakan masalah yang sangat penting harus diperhatikan pada kendaraan, emisi gas buang dan konsumsi bahan bakar kendaraan baru maupun lama tergantung pada proses pembakaran, Proses pembakaran salah satunya dipengaruhi oleh proses masuknya campuran bahan bakar dengan udara kedalam silinder. Proses pembakaran sempurna terjadi apabila campuran bahan bakar dan udara tepat, pada kendaraan lama yang masih menggunakan sistem karburator seiring denganjangka waktu pemakaian tentu saja kualitasnya akan menurun dan mempengaruhi kinerja sistem pemasukan udara dan bahan bakar pada kendaraan sehingga akan mempengaruhi proses pembakaran pada kendaraan tersebut, oleh karena itu diperlukan suatu inovasi untuk kendaraan dengan sistim bahan bakar karburator agar emisi dan konsumsi bahan bakar spesifiknya dapat diperbaiki walaupun masa pakainya sudah cukup lama[1]-[3].

Maka dari itu peneliti tertarik untuk melakukan penelitian lanjutan dengan menggunakan Turbo Cyclone pada saluran Intake manifold mesin bensin 4 tak yang bertujuan untuk melihat apa pengaruhnya terhadap konsumsi bahan bakar dan emisi gas buang, penulis akan memberikan beberapa treatment pada saluran intake manifold, sehingga diharapkan dapat meningkatkan performa yang dihasilkan oleh kendaraan yang akan dijadikan objek penelitian. Treatment yang dimaksud adalah memberikan beberapa perlakuan pada intake manifold yaitu dengan memasang Turbo Cyclone pada saluran intake manifold yang akan dipasang sebelum karburator dan sesudah karburator.

\section{Mesin bensin 4 tak}

Mesin bensin (Petrol Engine) adalah mesin konversi energi yang mengubah energi kimia (campuran udara dan bahan bakar) menjadi energi mekanik melalui proses pembakaran dengan menggunakan bunga api busi.[4]

Mesin 4 langkah adalah mesin yang untuk menyelesaikan satu kali siklus kerjanya membutuhkan empat kali gerak bolak balik piston atau dua kali putaran poros engkol.[5]

\section{Konsumsi bahan bakar spesifik}

konsumsi bahan bakar spesifik adalah banyaknya bahan bakar yang terpakai perjam untuk menghasilkan setiap kW daya motor. Dapat dihitung dengan rumus.[4]

Dimana :

$$
\dot{\boldsymbol{m}}_{f}=\frac{v}{t} \rho \text { fuel } \times \frac{\mathbf{3 6 0 0}}{\mathbf{1 0 0 0}}[\mathrm{kg} / \mathrm{h}]
$$

$$
\begin{aligned}
& \dot{\boldsymbol{m}}_{\boldsymbol{f}}=\text { massa aliran bahan bakar }(\mathrm{Kg} / \mathrm{h}) \\
& \mathrm{v} \quad=\text { volume bahan bakar yang dikonsumsi (ml) } \\
& \mathrm{t}=\text { waktu yang digunakan (detik) }
\end{aligned}
$$


pfuel $\quad=$ massa jenis bahan bakar $($ pertalite $=0,77 \mathrm{gr} / \mathrm{cm} 3$ )

3600/1000 = bilangan konversi.

\section{Emisi gas buang mesin bensin}

Gas yang terdapat dalam gas buang mesin bensin terdiri dari gas beracun dan tidak beracun, gas beracun adalah NOx (Nitrogen Oksida), HC (Hidrocarbon), dan CO (karbon Monoksida) sedangkan yang tidak beracun adalah $\mathrm{N}_{2}$ (Nitrogen), $\mathrm{CO}_{2}$ (Karbon dioksida), dan $\mathrm{H}_{2} \mathrm{O}$ (uap air). [4]

Bensin adalah senyawa hidrokarbon, setiap HC yang terdapat di gas buang kendaraan menunjukkan adanya bensin yang tidak terbakar dan terbuang bersama sisa pembakaran.Apabila suatu senyawa hidrokarbon terbakar sempurna maka hasil reaksi pembakaran tersebut adalah karbondioksida $\left(\mathrm{CO}_{2}\right)$ dan uap air $\left(\mathrm{H}_{2} \mathrm{O}\right)$.[6]

\section{Proses pembakaran}

proses pembakaran adalah proses perubahan energi (change of energy)untuk menghasilkan kerja mesin.[4]Pembakaran di dalam silinder adalah reaksi kimia antara unsur yang terkandung di dalam bahan bakar, yaitu Hidro Carbon (HC) dengan udara atau oksigen yang diikuti dengan timbulnya panas. [6]Proses pembakaran terdidiri dari beberapa tahapan yaitu :Tahap pengapian (ignition), Tahap perambatan api (flame propagation), Tahap tekanan pembakaran maksimal (maximum combustion pressure), dan Tahap akhir pembakaran (end of combustion).[4]

\section{Sistem pemasukan}

Sistim pemasukan adalah sebuah sistem yang memiliki fungsi mengalirkan campuran udara dan bahan bakar ke dalam silinder dengan hambatan yang sekecil mungkin. Sistem pemasukan ini terdiri dari saringan udara, karburator atau throtle body, dan intake manifold. [6]

\section{Turbo cyclone}

Turbo cyclone adalah peralatan tambahan yang diletakkan pada saluran masuk.Sesuai dengan namanya, pemasangan Turbo Cyclone bertujuan untuk mendapatkan efek cyclone (pusaran) pada udara yang melewati saluran masuk sehingga pemcampuran bahan bakar dengan udara lebih homogen.[7]

Turbo Cyclone terbuat dari logam stainless steel yang mempunyai beberapa sirip/sudu dengan sudut kemiringan tertentu. Turbo cyclone mempunyai housing berbentuk lingkaran seperti pipa dan di bagian dalamnya terdapat sirip/sudu, sirip/sudu Turbo Cyclone tidak dapat bergerak, sudut kemiringan sirip/sudu Turbo Cyclone akan mempengaruhi kemampuan kerjanya sehingga harus diperhitungkan sedemikian rupa agar sudu Turbo Cyclone dapat bekerja semaksimal mungkin. [8]

\section{METODE PENELITIAN}

Penelitian ini digolongkan pada penelitian kuantitatif dengan metode eksperimen.Pada penelitian ini variabel bebas diberikan sebuah perlakukan dan diadakan evaluasi untuk melihat apa pengaruh dari perlakuan yang diberikan. Penelitian ini bertujuan untuk mengetahui pengaruh penggunaan Turbo Cyclone tehadap konsumsi bahan bakar dan emisi gas buang pada mesin bensin 4 tak. Dalam desain penelitian ini terdapat dua kelompok data yaitu kelompok eksperimen dan kelompok control.

Pada penelitian ini akan dilakukan penelitian pengaruh pemasangan turbo cyclone terthadap konsumsi bahan bakar dan emisi gas buang, mesin yang yang akan digunakan pada penelitian ini adalah sepeda motor Yamaha Jupiter MX dengan kapasitas mesin 135 CC, pada penelitian ini akan diberikan perlakuan berupa posisi pemasangan Turbo Cyclone, posisi pemasangan Turbo Cycone akan di tempatkan pada saluran masuk sebelum karburator dan sesudah karburator. 


\section{HASIL DAN PEMBAHASAN}

\section{Hasil}

Hasil eksperimen ditabulasikan dalam beberapa tabel. Data konsumsi bahan bakar ada pada tabel 1, tabel 2 dan tabel 3. Tabel 4, tabel 5 dan tabel 6 menunjukkan tabulasi emisi gas buang yang terdiri dari $\mathrm{CO}, \mathrm{HC}, \mathrm{CO}_{2}$ dan $\mathrm{O}_{2}$.

Tabel 1. Data konsumsi Bahan Bakar Kendaraan tanpa perlakuan

\begin{tabular}{|c|c|r|r|r|r|}
\hline \multirow{2}{*}{ Rpm } & Jumlah Bahan Bakar & \multicolumn{4}{|c|}{ Waktu (detik) } \\
\cline { 3 - 6 } & $(\mathrm{ml})$ & Uji 1 & Uji 2 & Uji 3 & Rata-rata \\
\hline 1300 & 50 & 1201 & 1128 & 1197 & 1175 \\
\hline 1500 & 50 & 1067 & 1007 & 1018 & 1031 \\
\hline 3000 & 50 & 552 & 558 & 1159 & 756 \\
\hline 4000 & 50 & 407 & 404 & 405 & 405 \\
\hline 5000 & 50 & 303 & 305 & 305 & 304 \\
\hline 6000 & 50 & 246 & 241 & 241 & 243 \\
\hline
\end{tabular}

Tabel 2. Data konsumsi Bahan Bakar Menggunakan Turbo Cyclone sebelum karburator

\begin{tabular}{|c|c|r|r|r|r|}
\hline \multirow{2}{*}{ Rpm } & Jumlah Bahan Bakar & \multicolumn{5}{|c|}{ Waktu (detik) } \\
\cline { 3 - 6 } & $(\mathrm{ml})$ & Uji 1 & Uji 2 & Uji 3 & Rata-rata \\
\hline 1300 & 50 & 1090 & 1089 & 1095 & 1091 \\
\hline 1500 & 50 & 1060 & 1095 & 1037 & 1064 \\
\hline 3000 & 50 & 599 & 592 & 596 & 596 \\
\hline 4000 & 50 & 419 & 420 & 424 & 421 \\
\hline 5000 & 50 & 307 & 309 & 307 & 308 \\
\hline 6000 & 50 & 233 & 237 & 240 & 237 \\
\hline
\end{tabular}

Tabel 3. Data konsumsi Bahan Bakar MenggunakanTurbo Cyclone setelah karburator

\begin{tabular}{|c|c|r|r|r|r|}
\hline \multirow{2}{*}{ Rpm } & Jumlah Bahan Bakar & \multicolumn{5}{|c|}{ Waktu (detik) } \\
\cline { 3 - 6 } & $(\mathrm{ml})$ & Uji 1 & Uji 2 & Uji 3 & Rata-rata \\
\hline 1300 & 50 & 1200 & 1217 & 1210 & 1209 \\
\hline 1500 & 50 & 1116 & 1120 & 1118 & 1118 \\
\hline 3000 & 50 & 625 & 627 & 623 & 625 \\
\hline 4000 & 50 & 440 & 442 & 445 & 442 \\
\hline 5000 & 50 & 315 & 320 & 318 & 318 \\
\hline 6000 & 50 & 248 & 250 & 250 & 249 \\
\hline
\end{tabular}

Tabel 4. Data emisi Gas Buang kendaraan tanpa perlakuan

\begin{tabular}{|c|c|c|c|c|}
\hline \multirow{2}{*}{ Pengujian } & \multicolumn{4}{|c|}{ Emisi Gas Buang } \\
\cline { 2 - 5 } & $\mathrm{CO}(\%)$ & $\mathrm{HC} \mathrm{ppm}$ & $\mathrm{CO}_{2}(\%)$ & $\mathrm{O}_{2}(\%)$ \\
\hline Uji 1 & 0,31 & 225 & 5,6 & 12,42 \\
\hline Uji 2 & 0,31 & 214 & 5,6 & 11,74 \\
\hline Uji 3 & 0,28 & 212 & 5,3 & 12,51 \\
\hline Rata-rata & 0,30 & 217 & 5,5 & 12,22 \\
\hline
\end{tabular}

Tabel 5. Data emisi Gas BuangMenggunakan Turbo Cyclone sebelum karburator

\begin{tabular}{|c|c|c|c|c|}
\hline \multirow{2}{*}{ Pengujian } & \multicolumn{4}{|c|}{ Emisi Gas Buang } \\
\cline { 2 - 5 } & $\mathrm{CO}(\%)$ & $\mathrm{HC} \mathrm{ppm}$ & $\mathrm{CO}_{2}(\%)$ & $\mathrm{O}_{2}(\%)$ \\
\hline Uji 1 & 0,50 & 278 & 4,7 & 12,94 \\
\hline Uji 2 & 0,45 & 254 & 4,3 & 13,30 \\
\hline
\end{tabular}




\begin{tabular}{|c|c|c|c|c|}
\hline Uji 3 & 0,49 & 317 & 4,8 & 12,66 \\
\hline Rata-rata & 0,48 & 283 & 4,6 & 12,97 \\
\hline
\end{tabular}

Tabel 6. Data emisi Gas BuangMenggunakan Turbo Cyclone setelah karburator

\begin{tabular}{|c|c|c|c|c|}
\hline \multirow{2}{*}{ Pengujian } & \multicolumn{4}{|c|}{ Emisi Gas Buang } \\
\cline { 2 - 5 } & $\mathrm{CO}(\%)$ & $\mathrm{HC} \mathrm{ppm}$ & $\mathrm{CO}_{2}(\%)$ & $\mathrm{O}_{2}(\%)$ \\
\hline Uji 1 & 0,11 & 205 & 2,8 & 15,86 \\
\hline Uji 2 & 0,15 & 200 & 1,9 & 17,45 \\
\hline Uji 3 & 0,09 & 190 & 3,4 & 15,14 \\
\hline Rata-rata & 0,12 & 198 & 2,7 & 16,15 \\
\hline
\end{tabular}

Analisis Data

Analisis data konsumsi bahan bakar dari tabel 1, 2 dan 3 dibandingkan dalam tabel 7 berikut ini.

Tabel 7. Analisis konsumsi bahan bakar

\begin{tabular}{|c|c|r|c|r|r|r|r|}
\hline \multirow{2}{*}{ Rpm } & \multicolumn{7}{|c|}{ Konsumsi bahan bakar } \\
\cline { 2 - 8 } & \multirow{2}{*}{$\begin{array}{c}\text { Jumlah } \\
\text { (ml) }\end{array}$} & \multicolumn{2}{|c|}{ Standar } & \multicolumn{2}{|c|}{$\begin{array}{c}\text { TC Sebelum } \\
\text { Karburator }\end{array}$} & \multicolumn{2}{|c|}{$\begin{array}{c}\text { TC Setelah } \\
\text { Karburator }\end{array}$} \\
\cline { 3 - 9 } & $\begin{array}{c}\text { Waktu } \\
\text { (detik) }\end{array}$ & $\mathrm{kg} / \mathrm{h}$ & $\begin{array}{c}\text { Waktu } \\
\text { (detik) }\end{array}$ & $\mathrm{kg} / \mathrm{h}$ & $\begin{array}{c}\text { Waktu } \\
\text { (detik) }\end{array}$ & $\mathrm{kg} / \mathrm{h}$ \\
\hline 1300 & 50 & 1175 & 0,118 & 1091 & 0,127 & 1209 & 0,115 \\
\hline 1500 & 50 & 1031 & 0,134 & 1064 & 0,130 & 1118 & 0,124 \\
\hline 3000 & 50 & 756 & 0,183 & 596 & 0,233 & 625 & 0,222 \\
\hline 4000 & 50 & 405 & 0,342 & 421 & 0,329 & 442 & 0,313 \\
\hline 5000 & 50 & 304 & 0,455 & 308 & 0,450 & 318 & 0,436 \\
\hline 6000 & 50 & 243 & 0,571 & 237 & 0,586 & 249 & 0,556 \\
\hline
\end{tabular}

Analisis persentase perbedaan jumlah konsumsi bahan bakar dari tabel 4, 5 diperoleh data tabel 8. Kemudian dari tabel 4 dan 6 diperoleh data tabel 9.

Perbandingan kondisi standar dengan pemasangan turbo cyclone sebelum karburator

Tabel 8. Perbandingan konsumsi bahan bakar kondisi standar dengan pemasangan turbo cyclone sebelum karburator

\begin{tabular}{|c|c|c|c|}
\hline \multirow{2}{*}{ Rpm } & \multicolumn{2}{|c|}{ konsumsi bahan bakar $(\mathrm{kg} / \mathrm{h})$} & \multirow{2}{*}{$\begin{array}{c}\text { persentase } \\
\text { perbedaan }\end{array}$} \\
\cline { 2 - 3 } & kondisi standar & $\begin{array}{c}\text { turbo cyclone } \\
\text { sebelum karburator }\end{array}$ & \\
\hline 1300 & 0,118 & 0,127 & $-8 \%$ \\
\hline 1500 & 0,134 & 0,130 & $3 \%$ \\
\hline 3000 & 0,249 & 0,236 & $5 \%$ \\
\hline 4000 & 0,342 & 0,329 & $4 \%$ \\
\hline 5000 & 0,455 & 0,450 & $1 \%$ \\
\hline 6000 & 0,571 & 0,586 & $-3 \%$ \\
\hline
\end{tabular}

Berdasarkan tabel 8 dapat dilihat bahwa pemasangan turbo cyclone sebelum karburator memberikan pengaruh pada konsumsi bahan bakar sepeda motor yamaha jupiter MX $135 \mathrm{cc}$, dari tabel terlihat bahwa pada putaran idle terjadi peningkatan jumlah konsumsi bahan bakar yang pada kondisi standar konsumsi bahan bakar 0,118 kg/h, setelah diberi perlakuan meningkat menjadi $0,127 \mathrm{~kg} / \mathrm{h}$ yang berarti konsumsi bahan bakar boros ini disebabkan oleh 
bertambahnya hambatan venturi akibat pemasangan Turbo Cyclone sebelum karburator sementara kecepatan aliran masih kecil sehingga tidak terjadi turbolensi aliran oleh Turbo Cyclone, sedangkan diputaran sedang terjadi penurunan jumlah konsumsi bahan bakar ini artinya konsumsi bahan bakar lebih irit, pada putaran 5000 Rpm penurunan konsumsi bahan bakar mencapai $5 \%$ yaitu dari $0,249 \mathrm{~kg} / \mathrm{h}$ tanpa perlakuan menjadi $0,236 \mathrm{~kg} / \mathrm{h}$ setelah diberi perlakuan, penurunan jumlah konsumsi bahan bakar pada putaran sedang ini terjadi akibat dari turbolensi aliran didalam saluran intake sehingga pencampuran bahan bakar lebih homogen.

Perbandingan komsumsi bahan bakar kondisi standar dengan pemasangan turbo cyclone setelah karburator

Tabel 9. Perbandingan konsumsi bahan bakar kondisi standar dengan pemasangan turbo cyclone setelah karburator

\begin{tabular}{|c|c|c|c|}
\hline \multirow[b]{2}{*}{ Rpm } & \multicolumn{2}{|c|}{ konsumsi bahan bakar $(\mathrm{kg} / \mathrm{h})$} & \multirow[b]{2}{*}{$\begin{array}{l}\text { persentase } \\
\text { perbedaan }\end{array}$} \\
\hline & $\begin{array}{l}\text { kondisi } \\
\text { standar }\end{array}$ & $\begin{array}{l}\text { turbo cyclone } \\
\text { sebelum } \\
\text { karburator }\end{array}$ & \\
\hline 1300 & 0,118 & 0,116 & $2 \%$ \\
\hline 1500 & 0,134 & 0,124 & $8 \%$ \\
\hline 3000 & 0,249 & 0,229 & $8 \%$ \\
\hline 4000 & 0,342 & 0,318 & $7 \%$ \\
\hline 5000 & 0,455 & 0,436 & $4 \%$ \\
\hline 6000 & 0,571 & 0,556 & $3 \%$ \\
\hline
\end{tabular}

Berdasarkan tabel 9 diatas dapat dilihat bahwa pemasangan Turbo Cyclone setelahkarburator memberikan pengaruh pada konsumsi bahan bakar sepeda motor YamahaJupiter MX $135 \mathrm{cc}$, dari tabel terlihat bahwa dari putaran idle sampai putaran tinggi terjadi penurunan jumlah konsumsi bahan bakar setelah diberi perlakuan, namun penurunan terbesar terjadi pada putaran sedang yang mencapai 8\% pada putaran $1500 \mathrm{Rpm}$ dan 3000 Rpm.

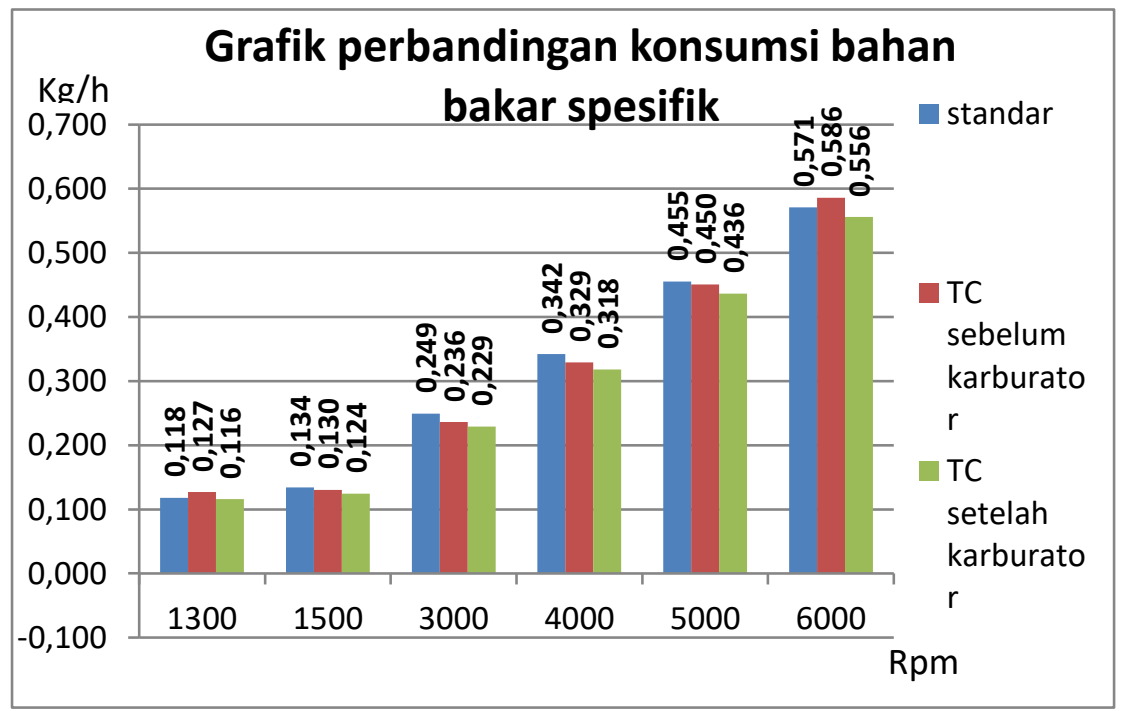

Gambar 1. Grafik perbandingan konsumsi bahan bakar. (sumber:hasil penelitian) 
Berdasarkan grafik dapat dilihat bahwa pemasangan Turbo Cyclone pada sepeda motor Yamaha Jupiter MX 135 cc baik sebelum karburator maupun setelah karburator sama-sama memberikan pengaruh terhadap emisi gas buang yang dihasilkan dibandingdengan kondisi standar sebelum dipasang Turbo Cyclone.

\section{Analisis emisi gas buang}

Tabel 10. analisi emisi gas buang

\begin{tabular}{|c|c|r|r|r|r|}
\hline \multirow{2}{*}{ Pengujian } & \multicolumn{4}{|c|}{ Emisi Gas Buang } \\
\cline { 2 - 6 } & $\mathrm{CO}(\%)$ & $\mathrm{HC} \mathrm{ppm}$ & $\mathrm{CO}_{2}(\%)$ & $\begin{array}{c}\mathrm{O}_{2} \\
(\%)\end{array}$ \\
\hline \multicolumn{2}{|c|}{ kondisi standar } & 0,30 & 217 & 5,5 & 12,22 \\
\hline \multirow{2}{*}{$\begin{array}{c}\text { Turbo Cyclone } \\
\text { sebelum } \\
\text { karburator }\end{array}$} & $\begin{array}{l}\text { Hasil } \\
\text { persentase } \\
\text { perubahan }\end{array}$ & 0,48 & 283 & 4,6 & 12,97 \\
\hline $\begin{array}{c}\text { Turbo Cyclone } \\
\text { setelah } \\
\text { karburator }\end{array}$ & $\begin{array}{c}\text { persentase } \\
\text { perubahan }\end{array}$ & 0,12 & 198,3 & 5,6 & 13,15 \\
\cline { 2 - 6 } & $61 \%$ & $9 \%$ & $-1 \%$ & $-8 \%$ \\
\hline
\end{tabular}

Berdasarkan data - data yang didapat dan dianalisis dapat dilihat bahwa pemasangan Turbo Cyclone pada sepeda motor Yamaha Jupiter MX 135 cc baik sebelum karburator maupun setelah karburator sama-sama memberikan pengaruh terhadap emisi gas buang yang dihasilkan dibanding dengan kondisi standar sebelum dipasang Turbo Cyclone namun pengaruh terbaik didapat dengan pemasangan Turbo Cyclone setelah karburator.

\section{SIMPULAN DAN SARAN}

\section{Simpulan}

Penggunaan Turbo Cyclone pada sepeda motor Yamaha Jupiter MX 135 cc baik sebelum karburator maupun setelah karburator sama-sama memberikan pengaruh terhadap konsumsi bahan bakar dan emisi gas buang.

Pemasangan Turbo Cyclone yang memberikan pengaruh terbaik untuk konsumsi bahan bakar adalah pada posisi setelah karburator, seperti yang terlihat pada grafik dimana pemasangan setelah karburator selalu menunjukkan jumlah konsumsi bahan bakar terkecil tiap Rpm yang diujikan dan persentase tertinggi juga didapat dari pemasangan setelah karburator dimana penurunan jumlah kunsumsi bahan bakar memcapai 8\% sedangkan pada pemasangan sebelum karburator menunjukkan peningkatan konsumsi bahan bakar pada putran idle dan putaran tinggi dan penurunan konsumsi bahan bakar hanya didapat pada putaran sedang (1500 Rpm-5000Rpm) dan hanya menunjukkan persentase tertinggi 5\%.

Untuk emisi gas buang karena fungsi dari Turbo Cyclone adalah merubah aliran udara didalam intake menjadi pusaran yang bertujuan untuk memperbaiki proses pembakaran didalam ruang bakar maka emisi yang jadi perhatian adalah gas $\mathrm{HC}$ dan $\mathrm{CO}_{2}$ karena gas $\mathrm{HC}$ merupakan bahan bakar yang tidak terbakar dan gas $\mathrm{CO}_{2}$ merupakan

indikator dari efisiensi pembakaran, sedangkan gas $\mathrm{CO}$ dan $\mathrm{O}_{2}$ dipengaruhi oleh perbandingan campuran sementara didalam penelitian ini perbandingan campuran tidak di rubah. Untuk gas HC karena HC adalah bahan bakar yang tidak terbakar maka jumlah yang baiknya adalah paling sedikit, dari hasil penelitian dapat dilihat bahwa penurunan gas HC diperoleh dari pemasangan Turbo Cyclone setelah karburator yang mencapai 9\% sedangkan pemasangan sebelum karburator meningkatkan kadar $\mathrm{HC}$ hal ini seiring dengan peninggkatan konsumsi bahan bakar pada putaran idle saat dipasangkan Turbo Cyclone sebelum karburator. Sedangkan untuk gas CO2 yng merupakan indikator dari proses pembakaran maka kadarnya 
yang baik adalah semakin banyak, dari hasil penelitian terlihat bahwa untuk gas $\mathrm{CO}_{2}$ hanya sedikit terjadi peningkatan yaitu hanya 1\% pada pemasangan setelah karburator namun pada pemasangan sebelum karburator terjadi penurunan yang besar mencapai $16 \%$.

Saran

Berdasarkan hasil penelitian yang telah dilakukan, maka peneliti menyarankan beberapa hal berikut : Penelitian ini masih terbatas pada objek penelitian sepeda motor Yamaha Jupiter MX 135 cc dengan sistem bahan bakar konvensional, sehingga dirasa perlu untuk melakukan penelitian pada kendaraan lain dengan teknologi yangterbaru, Dalam penelitian ini hanya menggunakan satu model Turbo Cyclone sehingga masih terdapat banyak jenis dan model dari Turbo Cyclone yang bisa diteliti dan Peneliti menyarankan jika ada yang ingin mengembangkan penelitian ini untuk membuat desain dari sudu Turbo Cyclone dengan hambatan sekecil mungkin.

\section{DAFTAR RUJUKAN}

[1] R. Afriwan, D. S. Putra, and M. Martias, "PENGARUH PENGGUNAAN VOLTAGE STABILIZER TERHADAP KONSUMSI BAHAN BAKAR DAN KANDUNGAN EMISI GAS BUANG PADA SEPEDA MOTOR HONDA VARIO 110 CC TAHUN 2009," Automot. Eng. Educ. J., vol. 2, no. 2, 2017.

[2] R. Ridwan, M. Martias, and A. Andrizal, "PENGARUH PENGGUNAAN TURBO CYCLONE TERHADAP KONSUMSI BAHAN BAKAR DAN KANDUNGAN EMISI GAS BUANG PADA SEPEDA MOTOR YAMAHA MIO SOUL," Automot. Eng. Educ. J., vol. 2, no. 2, 2017.

[3] W. Y. Youstisano, "Analisis Pengaruh Penggunaan Karburator Variasi terhadap Konsumsi Bahan Bakar SFC (Specific Fuel Consumption) Motor 4 Tak 200 CC," PhD Thesis, UNIVERSITAS MUHAMMADIYAH JEMBER, 2018.

[4] B. Amin and F. Ismet, Teknologi Motor Bensin. 2016.

[5] Wahyu Hidayat, Motor Bensin Modern. Jakarta: Rineka Cipta, 2012.

[6] Wardan Suyanto, Teori Motor Bensin. Jakarta: Depdikbud, 1989.

[7] N. A. Mufarida, "Analisis Prestasi Kerja Motor 4 Tak Dengan Penggunaan Turbo Cyclone," J-Proteksion, vol. 1, no. 1, 2016.

[8] Y. R. Fauzi, "Pengaruh Penambahan Turbocyclone Aksial Terhadap Aliran dan Performa Motor Bakar,” Turbo J. Program Studi Tek. Mesin, vol. 7, no. 1, pp. 25-31, 2018. 